\title{
The Ethos of 'the Queenslander': A Journey into the Art of Building in North Queensland
}

\author{
Stephen Naylor
}

Dr Stephen Naylor has worked as an educator and practitioner within the Visual Arts for more than 25 years in secondary education, TAFE and the university sector and has exhibited widely in the southern states. He has recently received a national Carrick Award for Excellence in Teaching and is an active member and promoter of regional community art activities. Over the last decade he has concentrated on writing about contemporary Australian art, extensively for Art Monthly and other national journals. He is a regular contributor to reviews on Australian representation in International Visual Arts events and has a particular interest in spatial theory. His doctoral research was based on Australia's representation in the Venice Biennale 1954 -2003; he is the Associate Dean Teaching and Learning in the Faculty of Law, Business and The Creative Arts and currently lectures in Art Theory in the School of Creative Arts Visual Arts at James Cook University, Townsville.

\begin{abstract}
In 1753 the Jesuit priest Marc-Antonie Laugier's published Essai sur l'architecture (Essays on Architecture) [1] a small philosophical text where he introduced the fundamentals of authentic architecture. Laugier recognised the gap between that which the natural world provides and the additional needs and features we must embrace to produce usable shelter. The general principles of architecture can be understood through the story of the 'rustic hut', suggesting that from our primal needs we have developed systems to create buildings. Our buildings are significant as they show an authentic account of who we are, how we see ourselves and how others see us. Buildings take the form of the clothes we wrap our families, pets and possessions within; they speak of culture, environment, history, struggles, triumphs and tragedies. Our domestic architecture in North Queensland is a living history of our relationships to materials, design, skills, technology, attitudes to houses and homes, rules and regulations, development, aesthetics, marketing and innovation.
\end{abstract}

\section{The buildings of North Queensland}

At a time when the periphery has become indeterminable from the centre, do we need to be fearful of the theoretical 'provincialism' raised by Terry Smith in his essay from 1974 The 
Provincialism Problem where he suggested that the outcome of styles accommodated outside of their genetic contexts as being 'intolerably self conscious'.[2]

As a new comer in 2005 to Northern Queensland my first point of connection to Townsville was through people, namely through my employment and the place where I choose to live. For me architecture or more precisely, domestic buildings have been important markers of community and culture in every place I have ever settled. Between cyclones and property developers the Townsville region, in particular sections, seemed incredibly distinct and worthy of investigation.

The concept of the built environment and architecture being recognised as cultural markers is not new. Chris Abel (1997) stated:

Various analogies have been drawn between the symbolic functioning of architecture and the formation of personal and social identities. Their accumulation has reached the point where the idea of 'architecture as identity' now rivals that of 'architecture as space' and 'architecture as a language' as one of the principal metaphors and themes in architectural discourse.[3]

Creative individuals have often sought to render their locality as subject, and in effect they become central in a narrative of space. The vernacular architecture of North Queensland that has developed since the mid 19th century has evolved through the initial recognition of the indigenous people of the region, as they sought shade and opportunities for breezes to assist in the creation of comfortable shelter. More often the large canopy of a tree with a raised platform above ground level provided the basis for sensible architecture, this was in opposition or contestation to the traditional western model of building dominated by enclosure of walls and roofing.

Since the early days of white settlement many local artists have been obliged to render the built environment through their artistic practice because of its power to express an authentic view of life in the tropics. One of the earliest works held in the City of Townsville Collection is a drawing of The Station at Townsville, Queensland, by Mark Watt Reid 1863, capturing a view of early domestic architecture. The quest by artists to represent the dwellings of North Queensland has continued to the present day with a concerted effort to capture high or low set buildings in all of their glory, some of this work verges on provincial or jingoistic. However many artists escape this taint, including the paintings of Ray Crooke, Ron McBurnie's prints, 
some interiors by Andrea Coates, and the paintings by Anneke Silver and Jan Hynes. It is through an alternative filter, be it material culture or artistic representation, that we can gain an appropriate model to experience the sense of place and identity and ultimately gain an insight into our futures.

Buildings and shelter are outward expressions of the people who inhabit the land; they speak of connection with place and relationships with both the social and fiscal economy.[4] The respect and comprehension of living in the tropics is dependent upon the knowledge we develop of the climate, physical geography, seasons and the psychology of the place.[5]

This paper reveals new ways of looking at our architecture; to see how necessity has shaped buildings, but also how creativity and aesthetics have added to our rudimentary architecture to turn our houses into iconic homes. The underlying question of 'What killed the Queenslander?' was the main theme of a recent symposium conducted in Townsville in conjunction with the Q150 exhibition The Art of Building in North Queensland.[6] The question was posed to challenge North Queenslanders into re-establishing a connection to the art of building as opposed to the consumption model which is now pervasive in many suburban developments. Over 100 members of the Townsville community attended the symposium conducted on Saturday $19^{\text {th }}$ September, 2009 with a range of presenters from academics, historians, artists, contemporary architects, designers, developers, local government, sustainability professionals and innovative builders.[7] 


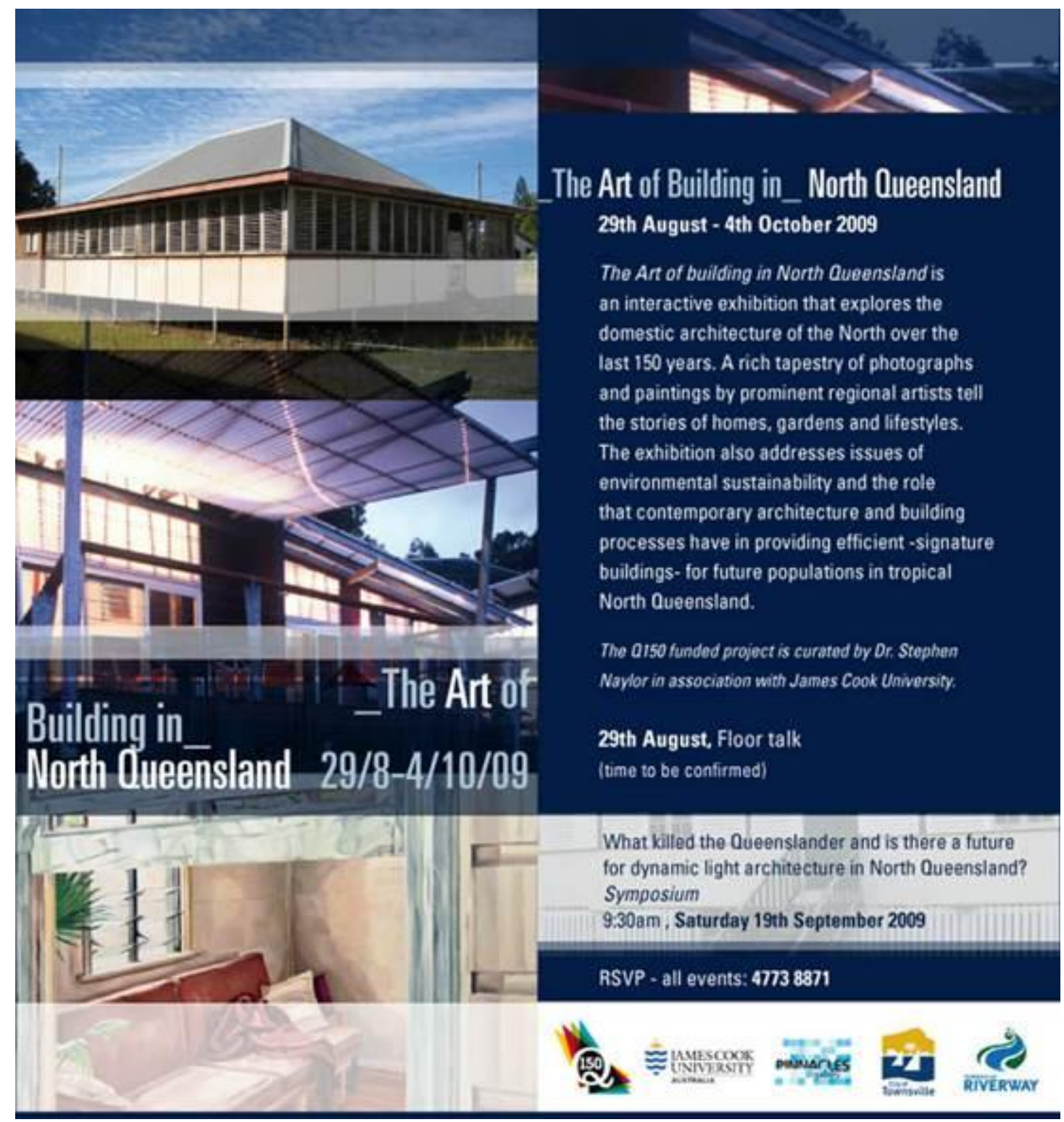

The general principles of architecture can be understood through the story of the 'rustic hut', suggesting that from our primal needs we have developed systems to create buildings. 8 Laugier (1753) argued that the concept of building was embedded in the understanding of the link between geography and construction; and how the qualities of the land/climate and the properties of natural materials and construction techniques could be integrated to improve ones opportunities for peaceful and plentiful living. The Art of Building in North Queensland revealed domestic architecture is a living history, one which shows our relationships to materials, design, skills, technology, attitudes to houses and homes, rules and regulations, development, aesthetics, marketing and innovation.

In North Queensland the climate provides a different set of parameters to those in the southern states; this has prompted a unique form of building, one adapted for a tropical 
climate but rooted in a western culture. The 'Queenslander' as it has been affectionately known, has emerged through necessity and adaptation.[9] In the early twentieth century, the Anglo-Indian Bungalow style used in Darwin, with its central room surrounded by verandas became a standard architectural model, however in mid 1930's through the stylistic intervention of the Wilfred Thomas Haslam, Senior Architect with the Commonwealth Department of the Interior, a new style was developed after recognising the merit of Malay buildings and their functionality in tropical conditions. This style became known as the Anglo-Asian derivation and is characterised by demarcated functional spaces, a template for the house we see now as the modern Queenslander.[10]

The other feature to recognise in the history of building in Queensland is its distinctive reliance on timber as the principle medium for construction. In 1911 almost $80 \%$ of all houses in Queensland were made from timber compared to the national average of $55 \%$. The abundance of the natural renewable material allowed numerous mills and timber companies to grow; these were augmented by builders and prefabrication companies that adopted set designs suitable for the tropical market and a kit house industry developed. These simple designs were pre cut and dispatched with all basic structural materials and special stylistic features. Companies like James Campbell \& Sons, Brown and Broad and Townsville's own Rooney Brothers were examples of leaders in the industry.[11]

It is recognised that only a small percentage of Australian domestic houses are designed by architects and much of the Queensland catalogue is a result of an organic response to location, climate and availability of skilled builders and suitable materials. There is recognition that the state is the second largest in the continent with distances of almost 2000 $\mathrm{kms}$ from north to south and $1500 \mathrm{kms}$ from east to west highlighting both climate and geographic variation. Despite the numerous prefabricated houses, the vernacular miner's cottages, the outback homesteads and Anglo-Indian/Anglo-Asia bungalows the consistency of style is elusive. The eventual 'Queenslander' that we allude to as a style exists more as an ethos rather than a true style; it has been recognised where the architectural features include: high or low set buildings, exposed timber framing with lining boards facing the interior, $35^{\circ}$ $40^{\circ}$ pitch corrugated iron hip or gabled roof, usually a verandah is included either as an entry point to the building to shade the front of the house or a fully enclosed verandah encircling the entire building.[12] 
For more than 150 years most of the architecture of North Queensland, which is strung along the north eastern coastline, has been shaped by the tropical environment and the economic conditions of the time.[13] The region north of Cardwell is affectionately known as Far North Queensland (FNQ) and is renowned for its lush tropical environment. This region provides many challenges for domestic architecture as the wet tropics are characterised by high levels of solar radiation, cyclones, torrential rainfall during the wet season, high levels of humidity and limited air movement. Yet the exotic lifestyle of Far North Queensland is a magnet for many, perhaps because the notions of shade, ventilation and open plans which assist in coping with this challenging climate act on our primal comprehension of architecture taking on many of the characteristics of the rustic hut.

The primacy of our building ethos has been recognised by contemporary architects; in 1991 Richard Allom states 'The North Australian house however, with its focus on the verandah as a living space was in a privileged position to adopt the new architectural thinking'.114]

Despite the possibilities of embracing climate in more recent years air-conditioning has been seen as the default solution to all design failures. For many it is the saviour; however the transition from the artificial cold dry interior to the hot moist exterior can create undesirable affects for some, and limits the affect of living with a sense of place.[15]

In designing housing for the north the long temperate winter months of the Dry season have allowed populations to enjoy benign weather for almost nine months of the year with minimal need for elaborate architectural features to ward off the elements. However, the Arcadian life style of North Queensland shifts dramatically with the arrival of the Cyclone season which has placed a huge demand upon architectural design. Walls and roofs are the skins of our houses; they form the membrane which determines what comes in and what stays out. The challenge for architecture has always been to optimise these surfaces in maximising efficiency though recognising weight, durability, cost, appearance and locality. The tree has been the principle building material used throughout history; it provided posts, bark, split slabs and shingles, sawn timber, and more recently laminated products. For many years almost the entire shelter was made utilising the tree. The introduction of exposed stud walls with single skinned lining became a characteristic of early Queensland buildings creating a distinction between the north and south[16]. 
In recognising the importance of resources we are often drawn to the work of craftsperson's and artists to reveal the beauty of both natural and manmade materials, this is even more acute when we look at domestic building. Joseph Reser, whilst reflecting on the work of Ben Tupperbäumer states, 'Both trees and houses shelter us, encompass us, afford our needs. Our attention is drawn to these surfaces and textures, in part, by their juxtapositioning, the multiple and contrasting surfaces of butts, limbs, and boards, the rounds and squares and endgrains, and by the liminal shapes, patterns, seeming shadows of lives spent. [17]

In recent times the timber has declined as the principle material for wall construction and has been replaced by cement blocks. This change has been brought about by many issues including shortages of cheap timber and the ease of block construction. Building regulations also appear to favour block work construction in comparison to light frame design as it is deemed more cyclone proof and requires less engineering to satisfy building regulations. The demise of timber has also heralded a rejection of the Queenslander ethos quotes Hyde (2000)

Research has shown a kind of 'bunker mentality' where buildings are optimized for extreme wind conditions and not for the normal climate conditions, leading to poor thermal performance. The use of structural systems that are appropriate for the climate to promote the desirable climate modification strategies is preferable. This draws attention to the effects of wind forces on particular elements of the building [sic]. The designer can select where the stiff parts of the structure are located to assist with the integration of the climate modification strategies.[18]

The changes in roofing methodology have had a less dramatic shift in recent years. From the early cane, reed, grass and shingle coverings roofs quickly adopted the use of the corrugated iron which began to be available in the mid $19^{\text {th }}$ century. These initially shiny impervious surfaces reflected the relentless sunlight and resisted the rain. The lightweight sheets were easily nailed (and later screwed) into roof purlins creating a more robust skin for the shelter during cyclones and storms. The thermal possibilities of the material shed heat quickly when the sun set creating liveable conditions for settlers. High pitched roofs dispatched the torrential downpours during the wet season reducing the massive weight generated by heavy rainfall on the wall structures of the building. The necessities for spouting and gutters have been contested in some modern architecture with massive downpours overflowing guttering and compromising some structures; the absence of guttering is a common feature in many contemporary houses, especially in the signature ‘Troppo' designs.[19] 
Since World War 2 domestic architecture in North Queensland has shifted from a majority of light framed timber houses with broad pitched roofs perched on timber posts to the dominance of new cement block and slab construction on concrete foundations. Early examples reflect a modernist approach in that they acknowledge the new use of contemporary materials and mark a departure from that which reflected the past. This new style has emerged through a combination of new masonry technology, cost and availability of timber, changes in planning regulations, relatively inexpensive up front costs for air-conditioning products and a building industry which has shifted its focus away from traditional building skills that used to tailor for the construction of individual houses. The domestic building industry is now structured around large building companies working on development projects, capitalizing on economies of scale and making token alterations to generic prepackaged designs. The drift from master builders to sub contractors using new trade products designed for quick and simple fit outs has yielded a domestic housing style more akin to a type of 'Legoland'. North Queensland domestic housing now mirrors the domestic architecture of many southern cities and creates a homogenized building style which has become the norm throughout suburban Australia.

The light timber framed buildings of past eras have been largely banished in the architecture of the $21^{\text {st }}$ century, yet the climatic responsiveness of these poorly designed concrete block homes pose serious questions for our sustainable future.[20]

The challenge for architecture in North Queensland is to reflect upon the rapid development over the past 30 years in the housing market and to recognize the impact of an alien architecture that now dominates the suburbs. These cement buildings with dark 'Colorbond' truss roofs (almost devoid of eaves) defy the context and micro climate of the tropics, where poor initial design is compensated with a bank of split system air-conditioners. The building code for North Queensland virtually ignores the climate that is characterised by higher allyear-round temperatures with minor seasonal variation when determining energy ratings. Further to this the current standards for energy ratings of buildings are determine by the capacity of a building to hold a constant temperature through heating or cooling systems. The thermal performance simulation software rates designs solely upon the question "is this house efficient to close up and to heat or cool", which is based around an insulated, closed-in and air-conditioned or heated space.[21] 
The light framed building was an intelligent response to place and now seems to be overshadowed by the rampant development of the cement block and truss model that has proliferated in the last three decades. These buildings feature a deliberate non-alignment of prevailing breezes, houses orientated to maximise their footprint on the block of land without thought of climatic issues and the uniform street setbacks that generate such visual boredom. Cement slab foundations remove any under building drafts and facilitate better insect attack in the form of mosquitoes and sand flies from the miasma. The thermal mass is increased holding heat within the building to allow the split system refrigerative air-conditioning to demonstrate its full potential drawing heavily on power resources. The windows are small and often awning or sliding thereby reducing natural breezes. The truss roof either supports a dark tiled roof to add to the thermal ineffectiveness or a delightful dark blue, brown or other inappropriate colour bond derivative. The gardens are usually lush with large lawned areas and other succulent non indigenous species of plants and reflect a type of tribal uniformity as we drive through suburban ubiquity.

This tribal fascination for sameness mimics the Howard Arkley suburbia of southern regions however the charm is missing. Anneke Silver's 2006 exhibition UnFraming held at Perc Tucker Regional Gallery, commented on how our space is changing and perhaps the eventual consequences.[22]

It is the nexus between need and opportunity where regional art practice, under the guise of innovation, practicality, bricolage and vernacular, can make a contribution to the built environment and the artistic discourse. Regional discourses based on spatial practice could even contribute to the heterotopian value of a sustainable environment where the masses can participate in the actualisation of spatiality and celebrate regionalism without the taint of provincialism.

When we add to nature though our intervention of building we mark the land with a statement of consequence - it is this visual and conceptual marking of our social and built environment which must be holistically determined; for the generations to come we must acknowledge our history in designing for their future. 
[1] Laugier, Marc-Antoine. An essay on architecture. 1753. Documents and sources in architecture ; no. 1. Los Angeles: Hennessey \& Ingalls, 1977.

[2] Terry, Smith. "The Provicialism Problem." In Anything Goes: Art in Australia, 19701980. Ed. Paul Taylor. South Yarra, Vic: Art \& Text, (Originally Published Artforum 1974).

[3] Abel, Chris. Architecture and Identity: Towards a Global Eco-Culture. Oxford, [England]; Boston: Architectural Press, 1997.

[4] Abel, Chris. Architecture and Identity: Towards a Global Eco-Culture. Oxford, [England]; Boston: Architectural Press, 1997.

[5] Goad Philip and Patrick Bingham-Hall, Troppo: Architecture for the Top End, Pesaro Architectural Monographs. Balmain, N.S.W.: Pesaro Publishing, 1999. 123

[6] An exhibition of housing in Nth QLD held at Pinnacles Gallery. Riverway Complex Townsville (22 $2^{\text {nd }}$ August -3 October 2009) incorporating historic and contemporary building documentation and examples of artist's impressions and interpretations of the 'Queenslander'.

[7] NA, "Forum on Attributes of Queenslander," Townsville Bulletin 22/9/2009. 7

[8] Laugier, Marc-Antoine. An essay on architecture. 1753. Documents and sources in architecture ; no. 1. Los Angeles: Hennessey \& Ingalls, 1977.

[9] Wallace, M. "Sense and Sensibility in Queensland Architecture." Place MakersContemporary Queensland Architecture. Ed. Wallace M and Stutchbury S. Brisbane: Queensland Art Gallery, 2008. 13-19.

[10] David Bridgman, "The Anglo-Asian Bungalow in Australia's Northern Territory," Shifting Views: Selected Essays on the Architectural History of Australia and New Zealand, eds. Andrew Leach, Antony Moulis and Nicole Sully. St Lucia: University of Queensland Press, 2004. 167-177

[11] Peter Bell, A History of the Queensland House. Adelaide: Historical Research, 2002. 3639 
[12] Peter Bell, A History of the Queensland House. Adelaide: Historical Research, 2002. 14

[13] Peter Bell, A History of the Queensland House. Adelaide: Historical Research, 2002.

[14] Richard Allom, "Two Centuries of the North Australian House," The Australian

Dwelling, eds. Peter Freeman and Judy Vulker. Red Hill, A.C.T: Royal Australian Institute of Architects, 1991.58

[15] Goad Philip and Bingham-Hall Patrick. Troppo: architecture for the top end. Pesaro architectural monographs. Balmain, N.S.W.: Pesaro Publishing, 1999. 25, 103

[16] Peter Bell, A History of the Queensland House. Adelaide: Historical Research, 2002. p10

[17] Reser, J. "The scaffolding of memory, some thoughts on 'Little Dwellings.' An exhibition of sculptural work by Ben Tupperbäumer.". Brisbane 2008. 5.

[18] Hyde, Richard. Climate responsive design: a study of buildings in moderate and hot humid climates. London: E \& FN Spon, 2000.

[19] Goad, Philip, and Patrick Bingham-Hall. Troppo: architecture for the top end. Pesaro architectural monographs. Balmain, N.S.W.: Pesaro Publishing, 1999.

[20] Hyde, Richard. Climate responsive design: a study of buildings in moderate and hot humid climates. London: E \& FN Spon, 2000.

[21] Submission from Centre for Excellence in Tropical Design (CETD) to the ABCB. The Australian Building Codes Board (ABCB) is a joint initiative of all levels of government in Australia and includes representatives from the building industry. The Board was established under an Inter-government Agreement signed by the Australian, State and Territory governments in March 1994 and reaffirmed in April 2006.

[22] Naylor, S "Un-Framing," Eyeline.61 2006. 60. 